\title{
Review Article \\ Survey of Green Radio Communications Networks: Techniques and Recent Advances
}

\author{
Mohammed H. Alsharif, Rosdiadee Nordin, and Mahamod Ismail \\ Department of Electrical, Electronics and Systems Engineering, Faculty of Engineering and Built Environment, \\ Universiti Kebangsaan Malaysia, 43600 Bangi, Selangor, Malaysia
}

Correspondence should be addressed to Mohammed H. Alsharif; moh859@gmail.com

Received 24 August 2013; Revised 31 October 2013; Accepted 17 November 2013

Academic Editor: Khoa Le

Copyright (C) 2013 Mohammed H. Alsharif et al. This is an open access article distributed under the Creative Commons Attribution License, which permits unrestricted use, distribution, and reproduction in any medium, provided the original work is properly cited.

Energy efficiency in cellular networks has received significant attention from both academia and industry because of the importance of reducing the operational expenditures and maintaining the profitability of cellular networks, in addition to making these networks "greener." Because the base station is the primary energy consumer in the network, efforts have been made to study base station energy consumption and to find ways to improve energy efficiency. In this paper, we present a brief review of the techniques that have been used recently to improve energy efficiency, such as energy-efficient power amplifier techniques, time-domain techniques, cell switching, management of the physical layer through multiple-input multiple-output (MIMO) management, heterogeneous network architectures based on Micro-Pico-Femtocells, cell zooming, and relay techniques. In addition, this paper discusses the advantages and disadvantages of each technique to contribute to a better understanding of each of the techniques and thereby offer clear insights to researchers about how to choose the best ways to reduce energy consumption in future green radio networks.

\section{Introduction}

In the past few years, the cellular network sector has developed rapidly. This rapid growth is due to the increases in the numbers of mobile subscribers, multimedia applications, and data rates. According to [1], the data transmission rate doubles by a factor of approximately ten every five years. Figure 1 shows how the number of subscribers in cellular networks have increased [2].

The increase in the number of mobile subscribers has led to an increase in data traffic; as a result, the number of base stations (BSs) has increased to meet the needs of customers. Reference [3] describes the growth in the number of BSs in developing regions between 2007 and 2012, and forecasted that the total number of BSs would increase by over 2 million within this period. Most of the previous studies on this subject have focused on improving both system capacity and data rates, while neglecting the increasing demand of cellular networks for energy. This increasing energy demand has prompted considerable research on the subject of "green communications." This paper discusses the issue of energy efficiency in communications networks. Perhaps the two most important reasons to pursue the development of green communications networks are increases in carbon dioxide emissions $\left(\mathrm{CO}_{2}\right)$ and increases in operational expenditures (OPEX). $\mathrm{CO}_{2}$ emissions are mainly associated with off-grid sites that provide coverage for remote areas. Most such sites are powered by diesel-power generators. According to [4], in 2002, the amount of $\mathrm{CO}_{2}$ emissions associated with information and communication technology (ICT) was 151 $\mathrm{Mt} \mathrm{CO}_{2}$. The mobile communication sector was responsible for $43 \%$ of this total, and this proportion is expected to increase to $51 \%$ of the total, or $349 \mathrm{MtCO}_{2}$, by 2020 . With respect to the economics of the sector, [5] indicates that ICT currently consumes 600 TWh (Terawatt hours) of electrical energy and that this consumption is expected to increase to $1,700 \mathrm{TWh}$ by 2030 . Cellular networks represent the largest component of the ICT sector. Figure 2 illustrates the total electricity consumption by communication networks around the world. Energy consumption by cellular networks is expected to increase rapidly in the future if no measures are taken to alter this trend [6]. 


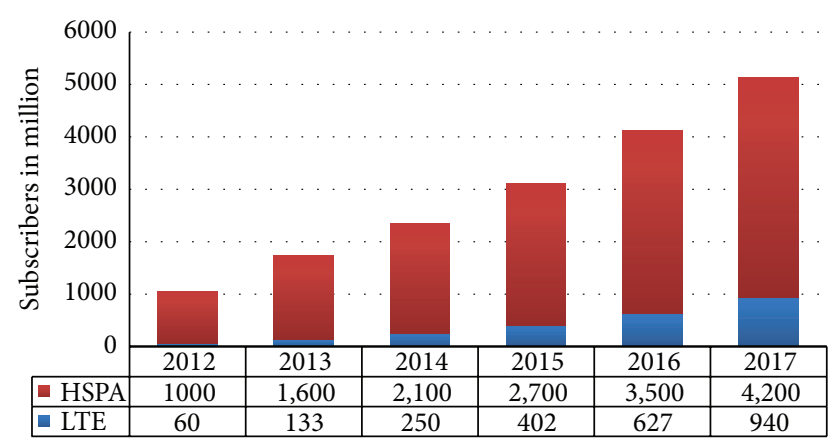

FIGURE 1: Growth forecasts for global HSPA and LTE subscribers, 2012-2017 [2].

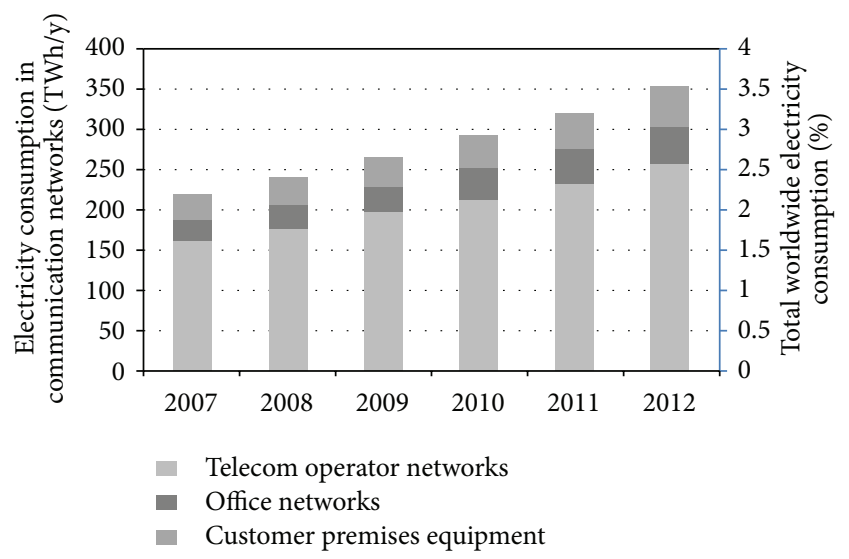

FIgURE 2: Worldwide electricity consumption by communication networks [6].

The above-mentioned statistics have motivated researchers in both academia and industry to develop techniques to reduce the energy consumption of cellular networks, thereby maintaining profitability and making cellular networks "greener." Reference [7] highlighted the goals associated with green cellular networks:

(i) improvement of energy efficiency,

(ii) improvement of the intelligence of the network through tradeoffs between energy consumption and external conditions, that is, traffic loads,

(iii) integration of the network infrastructure and network services to enable the network to be more responsive and to require less power to operate,

(iv) reduced carbon emissions.

As shown in Figure 3, the BS is the main energy consumer in a cellular network [8]. Reference [3] indicated that the numbers of BSs are increasing and will continue to increase in the future to guarantee the quality of service (QoS) expected by mobile subscribers. As a result, energy consumption by base stations will continue to increase. Therefore, an effort is required to reduce the energy consumption of base stations, while continuing to provide the expected quality of service, taking into account the associated cost. The energy consumed by a BS consists of two components. The fixed component

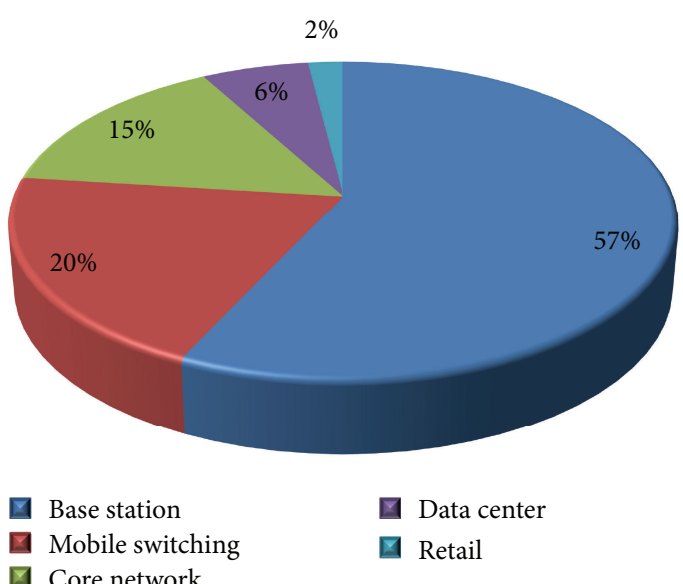

Figure 3: Energy consumption composition of a mobile operator.

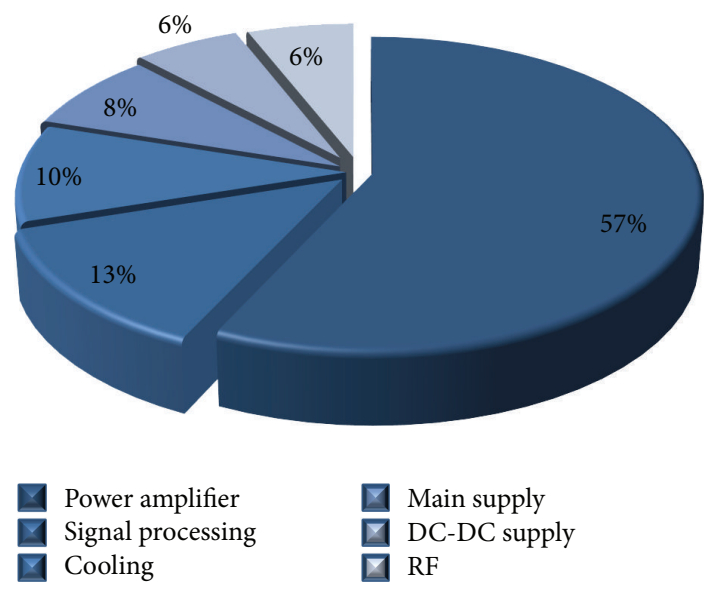

FIGURE 4: Distribution of energy consumption at a macrobase station site.

represents the energy consumed by the internal components of the BS, as shown in Figure 4, which require further classification of the components of BS sites and the energy consumption of each component. The dynamic component represents the energy consumed in RF transmission [9]. Thus, the solutions have two components: first, the hardware solution, for which the focus is on improving the energy consumption in the BS components, such as power amplifiers (PAs), digital signal processors (DSPs), cooling systems, and feeder cables and second, intelligent management of network elements based on traffic load variations.

In this paper, we provide a brief overview of the techniques that have been considered in previous studies for use in saving energy, including a discussion of the principles of operation, the advantages, and the shortcomings of each technique. The graph shown in Figure 5 classifies the different techniques that will be discussed in the following sections.

The remainder of the paper is organised as follows. Section 2 discusses energy efficiency metrics. The energy consumption in the internal components of a BS, especially the power amplifier, is discussed in Section 3. Sections 4 through 7 address time-domain energy-efficient techniques, 


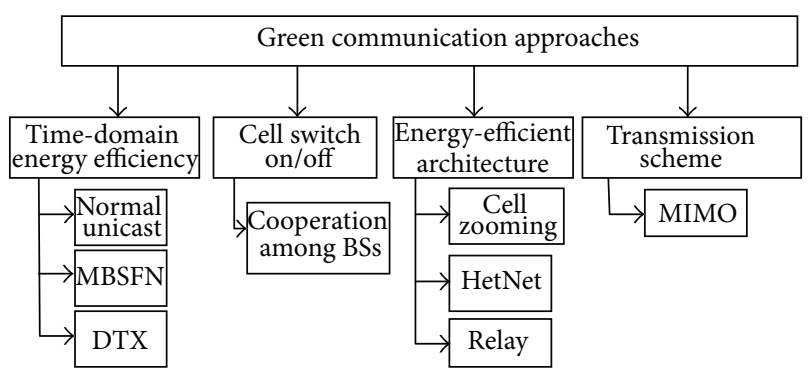

FIGURE 5: Classifications of energy-saving techniques.

cell switch on/off techniques, energy-efficient network architectures, and transmission scheme. Finally, we compare the techniques considered in Section 8 and highlight each technique's contribution to energy-efficient radio communication.

\section{Energy Efficiency Metrics}

Energy efficiency metrics provide information that can be used to assess and compare the energy consumption of various components of a cellular network and of the network as a whole. These metrics also help us to set long-term research goals for reducing energy consumption. With the increase in research activities pertaining to green communication and due to the intrinsic differences and relevance of various communication systems and performance measures, it is difficult for one single metric to suffice. Hence, several standardisation bodies and forums have considered energy efficiency in their network implementation strategies. However, energy efficiency metrics have been classified in three main categories in [10], that is, (i) facility-level, (ii) equipment-level, and (iii) network-level metrics. Reference [11], on the other hand, highlighted another type of metric, called the access-node level. The facility-level metric refers to high-level systems (such as data centres). The Green Grid (TGG) association of IT professionals proposed the metrics of power usage efficiency (PUE) and data centre efficiency (DCE) to evaluate energy efficiency in data centres [12]. Despite being a good metric for quickly assessing the performance of data centres at a macrolevel, PUE, which is defined as the ratio of total facility power consumption to total equipment power consumption, fails to account for the energy efficiency of individual pieces of equipment. Therefore, to quantify efficiency at the equipment level, a measure of the ratio of the energy consumption to the performance of a communication system would be more appropriate. Facility-level metrics assess initial power usage but do not reflect the energy efficiency of individual pieces of equipment. Thus, equipment-level metric, such as power amplifier efficiency metric, which quantify the performance of individual pieces of equipment, are required. The ATIS has introduced the telecommunications energy efficiency ratio (TEER), which is the ratio of useful work to power consumption and is measured in units of Gbps/Watt. Another equipment-level metric, the telecommunications equipment energy efficiency rating (TEEER), introduced by Verizon
Networks and Building Systems, quantifies the total energy consumption as the weighted sum of the amounts of energy consumed by the equipment under different load conditions. Another equipment-level metric is the energy consumption rating (ECR), which is the ratio of the energy consumption to the effective system capacity, measured in units of Watt/Gbps [13]. However, even the busiest networks do not always operate under fulload conditions. Therefore, it would be useful to complement metrics such as the ECR to incorporate dynamic network conditions such as energy consumption under fullload, halfload, and idle conditions. Other metrics suitable for these purposes include the ECRW (weighted ECR), ECR-VL (energy efficiency over a variable-load cycle), and ECR-EX (energy efficiency over an extended-idle load cycle). Hence, ECR provides manufacturers insight into the performance of hardware components. However, these metrics (ECR, TEER, and TEEER) are unable to capture all the properties of a system. While the definitions of energy efficiency metrics at the component and equipment levels are fairly straightforward, it is more challenging to define energy efficiency metrics at the system or network level. Networklevel metrics assess energy efficiency at the network level by considering the features and properties of the capacity and coverage of the network. The ETSI has defined two network-level energy efficiency metrics. The first metric is the ratio of the total coverage area to the power consumed at the site and is measured in units of $\mathrm{km}^{2} /$ Watt. The second metric is the ratio of the number of subscribers to the power consumed at the site and is measured in units of users/Watt [10]. Some specific metrics have been used to measure the performance of computing processing associated with energy consumption, in units such as millions of instructions per second per watt (MIPS/W) and millions of floating-point operations per second per watt (MFLOPS/W) [10]. Reference [14] highlighted a metric with units of energy per bit per unit area $\left(\mathrm{J} / \mathrm{bit} / \mathrm{m}^{2}\right)$. This metric relates energy consumption to the number of transferred bits and the area of coverage. This is equivalent to analysing the average power usage with respect to the average rate and the area of coverage $\left(\mathrm{W} / \mathrm{bps} / \mathrm{m}^{2}\right)$. A rich set of metrics exists at the access node level. The ECR quantifies the energy used to transmit a piece of information (Joules/bit). Some other metrics quantify the utility of various resources with respect to existing tradeoffs, such as the spectral efficiency $(\mathrm{b} / \mathrm{s} / \mathrm{Hz})$ and the power efficiency $(\mathrm{b} / \mathrm{s} / \mathrm{Hz} / \mathrm{W})$. One metric intended to cover all the aspects in a more general way is the radio efficiency $((\mathrm{b} \cdot \mathrm{m}) / \mathrm{s} / \mathrm{Hz} / \mathrm{W})[15]$, which reflects the data transmission rate and the transmission distance that is attainable for a given bandwidth and level of power supplied. To summarise the discussion above, a nonexhaustive list of energy metrics is given in Table 1. In addition, reference [16] discusses in detail the tradeoffs among several different energy efficiency metrics, such as deployment efficiency versus energy efficiency, spectrum efficiency versus energy efficiency, bandwidth versus power, and delay versus power. However, the most popular metric for measuring the performance of the system is "bits per Joule," which is the number of bits transmitted per Joule of energy. Interested readers can find a more comprehensive taxonomy of green metrics in $[14,17]$. Reaching a consensus 
TABLE 1: Classification of some energy efficiency metrics.

\begin{tabular}{|c|c|c|}
\hline Level & Units & Description \\
\hline \multirow[t]{2}{*}{ Facility level } & Power usage efficiency is a ratio $\geq 1$. & $\begin{array}{l}\text { Defined as the ratio of total facility power consumption to total } \\
\text { equipment power consumption }\end{array}$ \\
\hline & Data centre efficiency is a percentage (\%) & Defined as the reciprocal of PUE \\
\hline \multirow{5}{*}{ Equipment level } & PA efficiency is a ratio & The ratio of output to input power \\
\hline & W/Gbps & The ratio of energy consumption to effective system capacity \\
\hline & Gbps/W & The ratio of useful work to power consumption \\
\hline & MIPS/W & Millions of instructions per second per Watt \\
\hline & MFLOPS/W & Millions of floating-point operations per second per watt \\
\hline \multirow{4}{*}{ Access node level } & $\mathrm{b} / \mathrm{s} / \mathrm{Hz}$ & $\begin{array}{l}\text { Spectral efficiency refers to the rate at which information can be } \\
\text { transmitted over a given bandwidth in a specific } \\
\text { communication system }\end{array}$ \\
\hline & $\mathrm{b} / \mathrm{s} / \mathrm{Hz} / \mathrm{W}$ & The spectral efficiency per Watt \\
\hline & $(\mathrm{b} \cdot \mathrm{m}) / \mathrm{s} / \mathrm{Hz} / \mathrm{W}$ & $\begin{array}{l}\text { The radio efficiency measures the rate at which data are } \\
\text { transmitted and the transmission distance attainable for a given } \\
\text { bandwidth and power resources supplied }\end{array}$ \\
\hline & $J / b i t$ & $\begin{array}{l}\text { The energy consumption rating is defined as the number of bits } \\
\text { transmitted per Joule of energy }\end{array}$ \\
\hline \multirow{5}{*}{ Network level } & $\mathrm{km}^{2} / \mathrm{W}$ & The ratio of coverage area to site power consumption \\
\hline & $\mathrm{W} / \mathrm{km}^{2}$ & The power consumed per unit area \\
\hline & Users/W & $\begin{array}{l}\text { The ratio of users served during the peak traffic hour to site } \\
\text { power consumption }\end{array}$ \\
\hline & $\mathrm{J} / \mathrm{bit} / \mathrm{m}^{2}$ & $\begin{array}{l}\text { The energy consumption with respect to the number of } \\
\text { transferred bits and the coverage area }\end{array}$ \\
\hline & $\mathrm{W} / \mathrm{bps} / \mathrm{m}^{2}$ & $\begin{array}{l}\text { The average power usage with respect to the average } \\
\text { transmission rate and the coverage area }\end{array}$ \\
\hline
\end{tabular}

on a small set of standard energy metrics in future will not only accelerate research activities in green communications but also help to pave the way towards standardisation.

\section{Power Amplifier Improvement}

Several approaches to improving the energy efficiency of the internal components of a BS are discussed in [18, 19]. These approaches include reducing the amount of energy consumed by cooling systems, feeder cables, and power amplifiers (PAs). PAs have attracted the largest share of attention in previous studies because they represent the greatest proportion of the energy consumption of BSs. In mobile communications, the power amplifier in a macrobase station consumes the most energy, $65 \%$ of the total energy consumed by all BS elements, as shown earlier in Figure 3. Consequently, highly efficient power amplifiers are essential to reducing OPEX costs for mobile network operators. The most efficient PA operating point is close to the maximum output power (near saturation). Unfortunately, nonlinear effects and OFDM modulation with nonconstant envelope signals force the power amplifier to operate in a more linear region, that is, 6 to $12 \mathrm{~dB}$ below saturation [20]. In this subsection, we review several methods that have been used to improve power amplifier energy efficiency. The first technique, known as Doherty designs [21], is a special design technique used to improve PA energy efficiency. The use of Doherty designs has improved energy efficiency by 30 to $35 \%$ over a narrow bandwidth
[10]. The enhancement can be further improved to over $50 \%$ using a digital predistorted Doherty architecture and gallium nitride (GaN) amplifiers [22]. GaN is a special material used in the manufacture of PA transistors. The same energy efficiency enhancement has been achieved through the use of crest factor reduction (CFR) and digital predistortion (DPD) with Doherty PAs [18]. Reference [11] considered a class J amplifier, a switched-mode power amplifier (SMPA) and a drain modulation technique with higher energy efficiency than a predistorted Doherty amplifier and found that the class $\mathrm{AB}$ with digital predistortion improves the PA efficiency by $50 \%$. Ghannouchi et al. [23] proposed an inverse class $\mathrm{F}$ PA designed for WiMAX applications at a carrier frequency within a range centred at approximately $2.45 \mathrm{GHz}$. A detailed analysis and discussion of the classes can be found in [24]. In addition, it has been noted that many factors must be taken into account in PA design, including the following:

(i) high linearity, to satisfy higher-order modulation schemes,

(ii) greater average output power levels,

(iii) broader operating bandwidths, and

(iv) OPEX reductions achieved by decreasing BS energy consumption.

At present, PAs operate on high levels of DC power supply, independent of the traffic load. Thus, for a major part 
of the day, power is wasted [20]. The reduction in power consumption can be addressed in two ways. The first approach defines the operating point adjustment of power amplifiers needed to minimise the power consumption at arbitrary signal levels, so that the power efficiency is optimised for low, medium, and high traffic loads [25]. The second approach involves the deactivation of power amplifier stages to save power during time slots without signal transmission. More detailed analysis and discussion can be found in [26].

Despite many efforts, hardware technologies for reducing energy consumption at the base station have not been able to achieve significant energy savings. Moreover, one cannot ignore the amount of energy that is wasted by inefficient utilisation of resources. These factors have led to a solution that utilises both equipment-level and network-level approaches. The network-level approaches seek to tune network-related parameters based on the sensing of external conditions, which enables the determination of the optimal transmission strategies for energy savings. The philosophy behind all the proposed methods is the same, reducing energy consumption based on the traffic load. In the following section, we will review how network-level approaches can help to improve the energy efficiency.

\section{Time Domain Energy Efficiency}

Time-domain solutions seek to reduce the PA operating time by reducing control signals during low traffic or in the idlecase situation. Therefore, the amount of energy that can be saved using this approach depends on the PA offtime. In [27], the reduction in control signals with respect to the reference signals (RSs) was investigated. The uses of RSs in the network in this approach are listed as follows [28]:

(i) UE channel estimation (coherent demodulation of downlink transmissions).

(ii) UE cell-search measurements, both for neighbourcell measurements for handover and for measurements before initial access.

In the long-term evolution (LTE) system, each frame includes 10 subframes (from 0 to 9). In [28], three ways to reduce the number of RSs are discussed: (i) normal unicast, (ii) multicast broadcast single-frequency networks (MBSFN), and (iii) cell discontinuous transmission (DTX), also known as the "microsleep" technique in some of the references in [29]. Normal unicast RSs, inserted at the 0th, 4th, 7th, and 11th OFDM symbols at every subframe, have been applied to subframes 1-4 and 6-9 and not to subframes 0 and 5, due to the need to transmit RSs and control signals, such as the primary synchronisation signal, the secondary synchronisation signal, and the broadcast channel control. The second form of RS, known as MBSF, seeks to further decrease the power amplifier transmission time by reducing the number of RSs to 1 . If there are no active UEs in the idle traffic situation, there is no need to transmit RSs in subframes 1-4 and 6-9. This approach is the principle of DTX. Figure 6 illustrates the principles of these different techniques. In addition, Table 2 summarises the energy savings and on-time
TABLE 2: Energy savings and on-time PA for different time domain techniques.

\begin{tabular}{lcc}
\hline Technique & $\begin{array}{c}\text { On-time PA } \\
\text { in a frame (\%) }\end{array}$ & Energy savings (\%) \\
\hline Normal unicast & 47 & 40 \\
MBSFN & 28 & 55 \\
DTX & 7.1 & 85 \\
\hline
\end{tabular}

PA for each technique. Reference [30] determined some of the characteristics of these approaches, such as the impact on the specification, the impact on service, backward compatibility, and process time.

Similarly, in [31], switching off an optimum number of subframes per radio frame at low traffic loads was proposed.

Advantages. Clearly, this technique can result in a significant amount of energy savings in the idle traffic case. This means that it is an appropriate solution for rural areas. In addition, this technique saves energy in other components, such as ADC/DAC devices, DSP units, and cooling systems, during the switched-off periods.

Shortcomings. An insufficient quantity of RSs may cause some of the users to encounter problems during the synchronisation process with the BS, and thus, the UEs may be unable to enter into the DTX mode, thereby leading to a negative impact on the battery life of the UEs. In addition, some of the UEs may face difficulties in decoding the control signal.

\section{Cell Switch On/Off}

Switching off unused wireless resources and devices has become the most popular approach to reducing power consumption by cellular networks because it can save large amounts of energy. Cell switching is based on the traffic load conditions: if the traffic is low in a given area, some cells will be switched off, and the radio coverage and service will be provided by the remaining active cells. Therefore, the active cells will increase their transmission power to cover the area of the inactive cells. This may lead to a lack of coverage, because the BS maximum power is limited. A recent solution to this problem has been published in [32]. The authors propose an optimisation approach that achieves significant reductions in network energy consumption while abiding by the most important QoS constraints. The model proposed is a set of real-size universal mobile telecommunications system (UMTS) network instances consisting of various radio propagation environments. The results show that the proposed optimisation approach achieves significant reductions in network energy consumption (monthly energy savings between 35 and 57\%) while respecting the most important QoS constraints, such as full area coverage and guaranteed service rates.

Switching cells off can be accomplished in both singlelayer (macrocell) networks and multilayer network (such as HetNet). Reference [33] presents an overview of the energy savings achieved for a multilayer network. Obviously, not all 


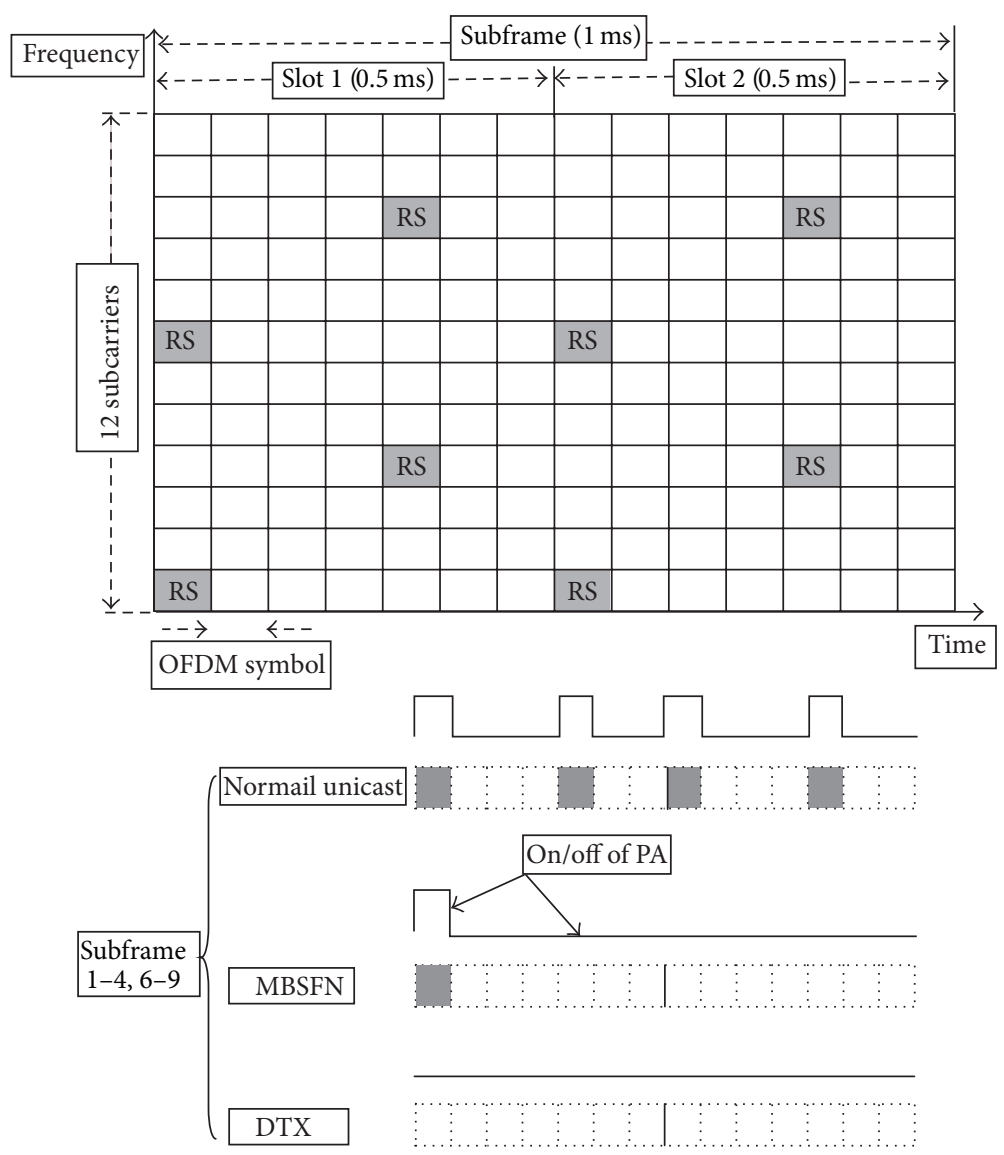

Figure 6: Time domain solution during idle and low traffic [27].

the cells in a network have the same capability to execute switch off/on operations. Accordingly, the network sites are classified as coverage sites or capacity sites. Capacity booster cells can execute switch off/on operations in accordance with the operator's deployment policy, while coverage is guaranteed by coverage cells.

Conditions of Cell Switch off/on. Both eNB and operation, administration, and maintenance (OAM) systems can initiate cell switch off/on operations in response to various trigger mechanisms. The eNB depends on the real-time traffic load of its cells, while OAM systems depend on the historical statistics for the traffic load of a wide range of cells.

Cell Deactivation. The eNB will notify its neighbouring eNBs by $\mathrm{X} 2$ signalling to inform them that a specific cell will be switched off. The neighbouring eNBs will not allow their resident UEs to hand over control to that cell. In OAM systems, cell deactivation is initiated by explicit OAM commands for cell deactivation that are transmitted via Itf-N and then set down to the eNB. When the eNB successfully or unsuccessfully switches off the cell, it will return a response signal to the OAM system.

Cell Activation. It is initiated by the neighbouring eNB's trigger mechanism, which monitors the traffic load in the same area. An explicit X2 signalling message concerning cell activation is expected to request that the eNB that is in the cell deactivation state switches on to the original state again, that is, becomes active. Therefore, the neighbouring eNBs will allow their resident UEs to hand over control to this recovered cell again. For OAM, cell activation is similar to the cell deactivation that is initiated by the OAM's trigger mechanism. When the eNB successfully or unsuccessfully switches on the cell, it will return a response signal to the OAM system.

Reference [34] provides an overview of the cell on/off switch schemes or macrosleep in a single-layer network and describes how, when, and where to apply them in the scenario for rural macrocells at low traffic loads. It is important to keep in mind that in real networks, it is impossible to switch off a random number of BSs because switching off is restricted by their configuration. The energy savings in this approach depends on the number of cells that will be turned off. If a large number of cells are turned off, then the energy savings will be substantial. In addition, a tradeoff between the number of cells that will be turned off and the QoS should be considered, as discussed in [35]; accounting for this tradeoff it can achieve energy savings of $50 \%$. The same authors, in [36], improved on their idea by introducing two different scenarios based on the UMTS network environment. The uniform scenario is based on the deployment of several identical microcells and a hierarchical scenario. In this scenario, an amendment to the topology 
of the network is implemented so that it contains one umbrella-cell overlap with many of the microcells. Marsan et al. demonstrated in [37] how to optimise energy savings by assuming that any fraction of cells can be switched off according to a deterministic traffic variation pattern over time and demonstrated that this approach can reduce energy consumption by between 25 and 30\%. Reference [9] describes a study of the optimal number of active BSs that would be deployed based on the tradeoff between fixed power and dynamic power. Under various traffic load conditions, the energy savings can range from $12 \%$ to $40 \%$. Reference [38] proposed the use of BSs with sleep/wake-up technology. A BS runs in active, sleep, or off mode depending on the traffic load. Each BS is augmented with an extra functional component, known as the "sleep/wake-up module," which is mainly used when the BS enters the sleep or wake-up mode. The energy consumption of the BS can be reduced by $72.9 \%$ using this strategy. Bousia et al. in [39] proposed a switching-off decision based on the average distance between BSs and UEs, whereby the BS at the maximum average distance will be switched off. This technique can achieve a reduction of up to $29 \%$ in energy consumption. Most of the previous studies that have discussed the energy efficiency problem have assumed that the conversion from switched on to switch off is instantaneous. Note that the switching period is very important because of its direct impact on the UEs in the cell. Reference [40] investigated the average time required for the implementation of the BS switch off by taking into account the handover process from the switchedoff BS to a new BS. In addition, [30], the processing time, which takes between 50 and $100 \mathrm{~ms}$ of handover (HO) time, was highlighted. Reference [41] proposed three scalable BS switch-off patterns to reduce the power consumption of cellular networks during off-peak hours with the QoS of those switched-off cells guaranteed by focusing on the worstcase transmission/reception locations instead of calculating spatial averages. In addition, BS cooperation is used to efficiently extend the network coverage to the service areas of the switched-off cells. A potential power savings of up to $50 \%$ was observed in the numerical results.

Advantages. As mentioned earlier, the PA consumes the most power in a BS. Therefore, the cell switch-off approach achieves a good balance between performance, by providing coverage from neighbouring cells, and energy savings, by switching off some of the cells.

Shortcomings. Based on the traffic load, some cells are inactive and others are active; therefore, the active cells will increase their transmission power to cover the areas not covered by the inactive cells. There are several drawbacks to this method. First, the BS maximum power is limited; accordingly, there will be some areas without coverage, which can contribute to a decline in the quality of service. Second, the increase in power of the active cells reduces the energy savings. Finally, this approach reduces battery life for users because they require higher receiver power to connect with the other cells, which can be located at long distances away from them.

\section{Energy-Efficient Architecture}

This approach is considered a special case of the cell switchoff approach. The principle of this approach depends on the cooperation of the BSs to provide service to the users and provide energy savings in the event of low traffic. In this section, we present cell zooming, heterogeneous networks (HetNets), and relay techniques.

6.1. Cell Zooming. References $[42,43]$ proposed a cell capability to allow for the adjustment of the size of the cell according to the traffic load. When congestion occurs at the cell due to an increase in the number of UEs, the congested cell could zoom in, while the neighbouring cells with smaller amounts of traffic could zoom out to provide the coverage for UEs that cannot be served by the congested cell. If the neighbouring cells can provide coverage without the congested cell zooming in, then the congested cell can enter into sleep mode to reduce energy consumption. The major component of this design is a cell-zooming server (CS). The CS is considered the brain in this approach because it decides when cell zooming occurs. In addition, the CS collects network information, such as information on the traffic load, channel conditions, and user requirements. The CS analyses these data to decide whether to zoom. If a cell needs to zoom in or zoom out, the cell action is coordinated with the actions of its neighbouring cells with assistance from the CS. If the cell needs to zoom out, the transmission power of the BS will be increased, in contrast to the zoom in mechanism [42]. However, if the cells that must zoom out to provide coverage to the neighbouring cells that have switched off cannot provide this coverage due to the limited maximum transmission power of the BS, then an increase in energy consumption occurs because the neighbouring cells are unable to switch off, and there are areas without coverage, that is, coverage holes. In [44, 45], this problem was addressed through the deployment of more small cells to further improve energy consumption; that is, more cells can be switched off than in the traditional scheme. However, as the number of small cells increases, the fixed power of the BSs (e.g., the power required for cooling and for the power supply) also increases.

Advantages. This technique can improve the throughput and lengthen the UE's battery life.

Shortcomings. There are several drawbacks, as this physical adjustment technique depends on the transmission power of the BS. The BS's maximum transmission power is limited. In addition, when the remaining active cells increase their power during the zooming-out period, a problem of intercell interference emerges. Inter-cell interference occurs when all the neighbouring cells zoom out during the same time interval.

6.2. Heterogeneous Networks (HetNets). Heterogeneous networks have a layered structure that combines different networks to serve the same mobile devices. Heterogeneous networks are intended to improve both throughput and energy consumption through the deployment of a network of cells 
TABLE 3: Cell size and transmitted power for a heterogeneous network [20].

\begin{tabular}{lcc}
\hline Cell type & Cell size & Output power \\
\hline Macro & $1-30 \mathrm{~km}$ & Tens of watts \\
Micro & $0.4-2 \mathrm{~km}$ & $1-6.3 \mathrm{~W}$ \\
Pico & $4-200 \mathrm{~m}$ & $200 \mathrm{~mW}-2 \mathrm{~W}$ \\
Femto & $10 \mathrm{~m}$ & $20-200 \mathrm{~mW}$ \\
\hline
\end{tabular}

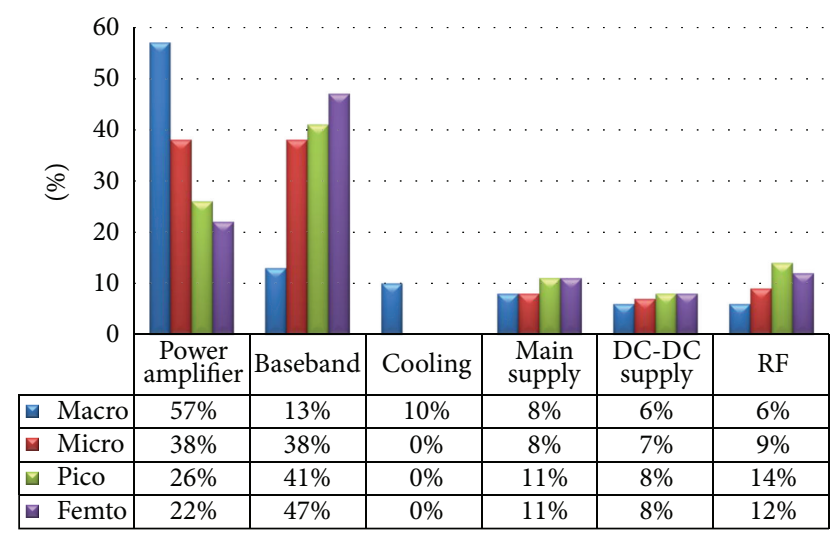

FIGURE 7: Power consumption of the hardware elements of LTE BSs for different BS types [20].

of small size (such as micro-, pico-, and femtocells). These cells vary in size, output power, and data rate, as indicated in Table 3. Figure 7 illustrates the power consumption of the hardware elements in LTE BSs for different BS types.

The mechanism of these networks is further discussed in [33]. Macrocells are deployed to provide overall coverage, while small cells become active if the demand increases. Based on this approach, a joint deployment strategy was investigated in [46] utilising microcells within a macrocell network, and the impact on energy consumption was determined. In addition, the authors considered area power consumption as a performance metric. The same authors, in [47], investigated the same issue in more detail. They evaluated and optimised the average number of microsites per macrocell. References [48, 49] investigated the energy efficiency of both homogeneous (pure microcells and macrocells) and heterogeneous networks consisting of a varying number of microsites, based on the traffic load conditions. The results of the study indicated that homogeneous microdeployment achieves better energy efficiency heterogeneous network deployment. The literature indicates that as the throughput and number of users in the network increase, the best approach to improving the energy efficiency of the network is to deploy more microsites. In addition to the above-mentioned studies, several papers have highlighted the feasibility of using pico- and femtocells to achieve energy savings. Femtocells are the subject of the largest share of these discussions in the literature. Femtocells are the closest to the users in terms of network size; that is, the distances are shorter, which results in less power transmission, thereby increasing energy efficiency and reducing the path loss. This reduced path loss improves the throughput of the network, as discussed in detail, along with other points, in [50]. Calin et al. [51] provided an overview of a joint deployment of femto- and macrocells. In addition, in [52, 53], the energy efficiency gains that can be achieved through the deployment of femtocells within a microcell, while accounting for the QoS, was discussed. The results indicated that the use of femtocells improved the energy consumption of the joint network deployment studied. Reference [54] proposed a new architecture called "FemtoWoC" to improve the energy efficiency through wireless-over-cable (WoC) transmission. Reference [22] examined the impact on energy efficiency of deployment of different picocell sizes in a macrocell. The simulation results obtained indicated that this approach can reduce energy consumption by $60 \%$ when used by $20 \%$ of customers within the picocell coverage area.

A recent study described in [55] offered excellent analytical models for the power consumption in macrocells, microcells, picocells, and femtocells. This paper discussed five classes of networks. For the class A network, the researchers considered a femtocell-based network in which, instead of macrocells, an area is fully covered by femtocells. The results showed that energy consumption was reduced by $82.72-$ $88.37 \%$. In the class B network, the coverage area was divided into three parts: an urban area, a suburban area, and a rural area, which were covered by femtocells, macrocells and portable femtocells, respectively. The simulation results obtained show that the total transmitted power was reduced by $78.53-80.19 \%$. In the class $C$ network, femtocells, picocells, microcells, and portable femtocells were allocated in a densely populated urban area, sparsely populated urban areas, suburban areas, and rural areas, respectively, which reduced the total transmitted power by $9.19-9.79 \%$. In the class D network, microcells, picocells, and femtocells were allocated to border regions and macrocells were allocated to the rest of a coverage area. The simulation results obtained showed that the total transmitted power was reduced by $5.52-$ $5.98 \%$. In the class E network, femtocells were allocated to the boundary region of the macrocell and turned on in that region when the signal received from the macrocell BS was too low to successfully receive or generate a call. When all the femtocells were kept on, the macrocell shrinks in coverage area. The simulation results obtained showed that power consumption was reduced by $1.94-2.66 \%$.

Advantages. A smaller cell size leads to improvement in coverage and capacity for the following reasons: lower transmission power, higher SINR, higher spectral efficiency, low path loss, prolonged handset lifetime (due to short transmit-receive distances), and smaller cells with lower costs.

Shortcomings. Despite the benefits that can be achieved by this technique, there are some challenges that need to be addressed, including management of the interfaces between heterogeneous environments and the dead zone problem.

6.3. Relay. Relay techniques are other means of saving energy, while improving network performance. The principle of this class of techniques is based on the deployment of relay nodes between the source (BS) and the destination (UEs). 
Relay nodes are intended to save energy, while increasing the network throughput by providing short transmission distances and thereby reducing path loss. In addition, the relay architecture reduces inter-cell interference due to low transmission power. There are two types of relay structures, namely, (i) pure relay systems and (ii) cooperative relay systems. A pure relay system is composed of small linked relay nodes between the BS and the UEs. Pure relay systems have been found to be more efficient than cooperative systems, and in some cases, a net power gain can be achieved for highly efficient relays. Additional benefits can be achieved when deploying relays to cover network traffic hotspots. In addition, managing sleep mode during MBSFN subframes is seen as a promising tool for mitigating the power consumption of relay nodes and increasing the benefits of their usage. Finally, we found that in urban and suburban environments, relay nodes can satisfy the needs of increasing traffic demand by providing higher energy efficiency without compromising the QoS and the system capacity [56]. In a cooperative relay system, several UEs act as the relay nodes and form a cooperative network. The cooperative relay technique provides path independence among different fading channels (a fundamental aspect of the diversity gain concept), thereby achieving energy savings [57]. Reference [56] highlighted the implementation of relay schemes for inbuilding deployment, which can increase energy efficiency in comparison to $\mathrm{P} 2 \mathrm{P}$ communication. The literature suggests that the most important parameters in the design of relay networks are the following: (i) the choice of the relay node, (ii) the relay strategy, and (iii) the allocation of power and bandwidth for each user. Reference [58] discussed the optimal allocation of energy and bandwidth for each user and the selection of the optimal relay node and the optimal relay strategy (i.e., decode and forward versus amplify and forward), taking into account both user traffic demand and the physical channel. Reference [59] discussed several relay strategies, including the most significant ones: (i) amplify and forward (AF), (ii) decode and forward (DF), and (iii) compress and forward (CF). Reference [20] investigated hybrid relaying schemes, which allow the relay to dynamically switch between DF and CF schemes according to its decoding status. The analysis results showed that hybrid relaying achieves better energy efficiency performance than DF and offers the best energy efficiency performance, especially at the cell edge. Reference [60] discussed the impact on energy efficiency of the number of hops, the locations of the hops, the allocated power, and the data rate of each hop. Reference [61] investigated the improvement in energy efficiency of the users achieved by allocation of the optimal power to maximise the energy efficiency (EE) of each user. The authors of reference [62] proposed an energy-efficient single cooperative relay selection that accounts for both the MAC layer protocol and the power control strategy when selecting the node. Reference [63] investigated the energy consumption of single hops with fixed transmission power and multihops with fixed transmission power and power control in CDMA cellular networks. The results indicated that multihop with power control is better in terms of energy consumption.
Advantages. Whenever the distance between the transmitter and the receiver is small, this technique provides high coverage and capacity. The advantages of this technique are the following: low transmission power, low interference, reduced path loss, and extended handset life.

Shortcomings. There is a tradeoff in achieving energy efficiency in terms of the number of nodes that are required in a relay scheme and the optimal relay configuration. With respect to cooperative relay systems, the first challenge is that the radio frequency resources for each user should be split for transmitting data both from the user and from the other users, and the second issue is to select an appropriate user to act as a relay node.

\section{Transmission Scheme}

Multiinput and multioutput (MIMO) has become the main feature of the evolution of the next generation of wireless networks. MIMO has the advantages of reducing fading and increasing throughput without it being necessary to increase either the bandwidth or the transmission power. These advantages can be achieved by introducing space-time coding (STC), which exploits spatial diversity to overcome fading by sending the signal that carries the same information through different paths, and by using spatial multiplexing (SM), which exploits multiple paths to send more information. In this subsection, we highlight the impact of MIMO transmission on energy efficiency. Reference [64] discussed a tradeoff between the diversity gain and the multiplexing gain in terms of the energy efficiency of wireless sensor networks. The discussion indicated that the energy efficiency of MIMO transmissions can be higher than that of single-input/singleoutput (SISO) transmission if the design is implemented properly. A significant energy reduction can be achieved if both diversity gain and multiplexing gain are used. The impact on energy efficiency of cooperative MIMO techniques with data aggregation for wireless sensor networks was discussed in [65], which demonstrated that energy consumption can be reduced by reducing the amount of data transmitted and by using an efficient resource allocation scheme. Cui et al. [66] presented an MIMO energy consumption model for both the transmitter and the receiver, based on Alamouti's diversity scheme. Using this model, the energy efficiency over various transmission distances was studied, and the energy efficiency values were compared with those obtained using a SISO system under the same conditions of throughput and BER. The results of the comparison suggests that MIMO is not always more energy efficient than SISO; indeed, at short distances, SISO may outperform MIMO in terms of energy efficiency. In addition, MIMO is not efficient for low traffic loads because it consumes more energy per circuit, as discussed in [67], in which switching between MIMO and SIMO under dynamic loads was studied. The results of the study indicated that SIMO achieves energy savings under low traffic loads. Some research studies have also focused on the traffic load adaptation of MIMO antennae $[68,69]$. Huawei and Samsung discussed several methods for allowing the BS to change the number of active antennae based on 


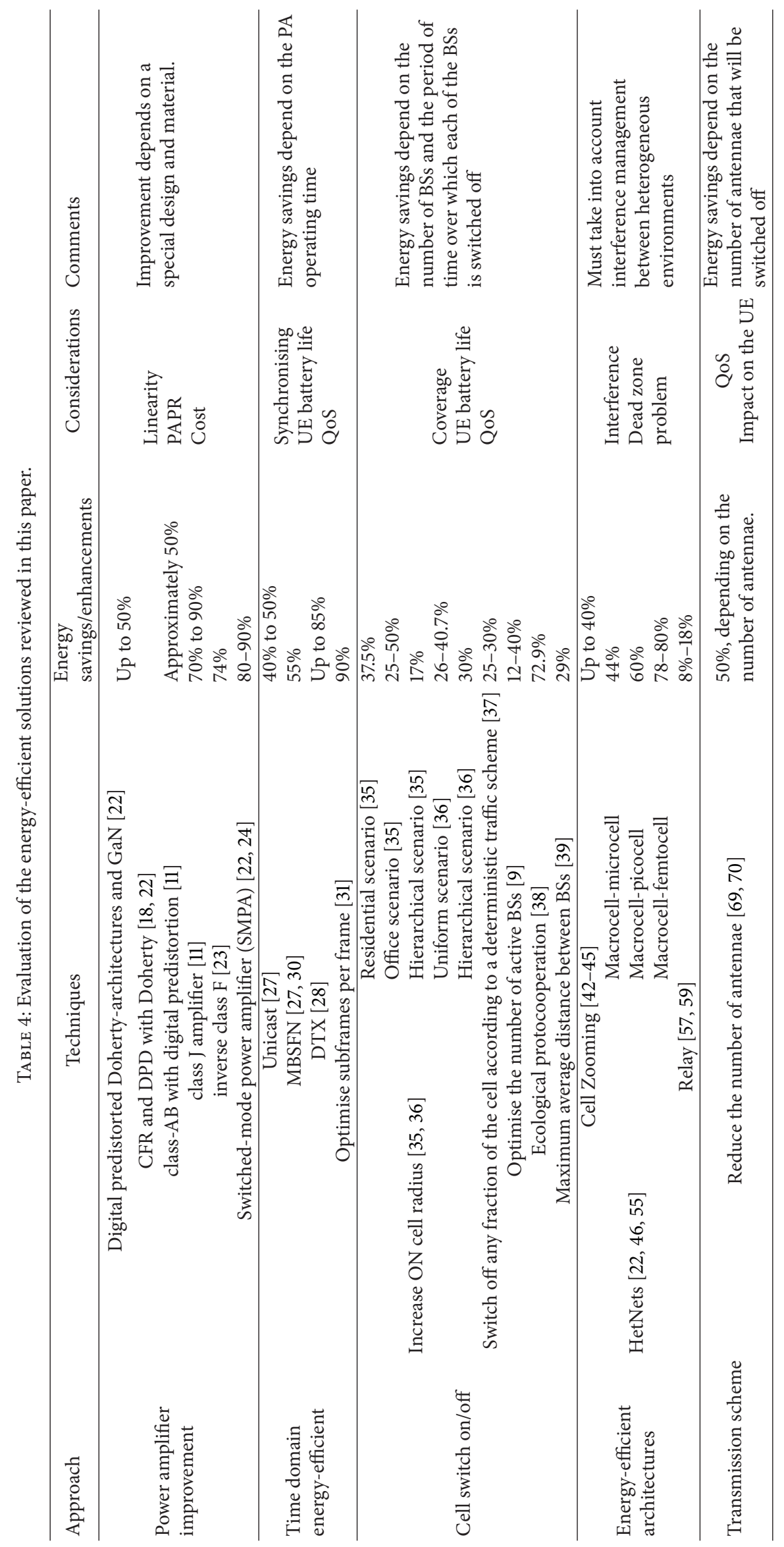


the traffic load conditions. Another approach is to reduce the number of antennae based on the ratio of switch-off RF power amplifier units, for example, switching from 4-antennae to 1-antenna transmission to reduce energy consumption to $1 / 4$ of the energy consumed in the 4-antennae case [70]. Each branch of a MIMO antenna is connected to a PA, and the $\mathrm{PA}$ is the component that consumes the most energy in a BS. Therefore, by using the adaptive MIMO approach, significant energy savings can be achieved during network operations. Details of the MIMO energy savings approach can be found in [69]. Reference [30] describes some of the benefits of this approach, such as improvements in energy savings, processing time, and the impact on network service.

Advantages. The MIMO scheme optimises the tradeoff between energy reduction and throughput, while reducing cochannel interference.

Shortcomings. There are some drawbacks to the reduced MIMO antenna approach, such as the need for a fixed antenna port during the active time of the BS and the requirement that the number of switched on/off antennae may be communicated to the UEs properly. Otherwise, the behaviour of the UEs will be impacted. In addition, a reduction in the number of antennae can result in service degradation or interruption during the antenna reconfiguration.

\section{Conclusions and Comparisons}

This paper presents an overview of the energy consumption problems of wireless communication networks and describes the techniques that have been used to improve the energy efficiency of these networks. Table 4 presents a summary of the techniques discussed in this paper. In addition, the table summarises the energy savings that can be achieved by each technique and other technical details that must be considered in improving energy efficiency.

Integration of multiple approaches based on changes in traffic load is possible and can help to maximise energy savings under low downlink traffic conditions. In addition, integrated solutions can combine component-, link- and network-level energy saving techniques. For instance, the cell switch-off technique with cooperation among mobile network providers is seen as having potential for implementation in industrial areas because the traffic loads in these areas are low for long periods of time, especially at night and over weekends and holidays. Preliminary studies have shown that this approach significantly improves energy savings, compared to a stand-alone solution. Nonetheless, there are issues that need additional investigation in future studies, such as resource management, increasing the load on the host network (due to its own customers plus roaming customers), and the ability to provide good service as well as handling of traffic data. Examples of such challenges include VoIP calls or video streaming with no delay, compatibility between signalling loads and channel capacity, and communication overhead due to handovers. Other important issues include the variation of mobile operator coverage and the types of services from one area to another. In addition, the tradeoff between computational complexity and the savings in required transmission power is an important issue. The complexity increases with the number of networks. Emphasis should be placed on designing low-complexity schemes, resulting in easy, viable implementations as well as gains in overall network-level energy efficiency.

In the same context, a BS can be configured to use a single antenna and the maximum number of MBSFN subframes in a frame. The challenges of this hybrid solution are the processing/interruption time and signalling for system reconfiguration and avoidance of adverse impacts on UE performance. The previously discussed hybrid approach of combining cell on/off switching with cell zooming can also be applied. Compatibility between the signalling load and channel capacity, intercell interference, coverage, and the maximum capacity achievable are all issues that need to be further studied and analysed thoroughly.

\section{Acknowledgments}

The authors would like to thank the Universiti Kebangsaan Malaysia for its financial support of this work under Grant Ref: UKM-GUP-2011-065. The authors also would like to thank the anonymous reviewers for their feedback.

\section{References}

[1] G. Fettweis and E. Zimmermann, "ICT energy consumptiontrends and challenges," in Proceedings of the 11th International Symposium on Wireless Personal Multimedia Communications (WPMC '08), pp. 1-6, 2008.

[2] V. Livingston, "HSPA and LTE mobile broadband in the Americas," in Proceedings of the Workshop of 4G Americas, 2012.

[3] Green Power for Mobile, GSMA, "Community Power Using Mobile to Extend the Grid," 2010, http://www.altobridge.com/ wp-content/uploads/2010/01/Community-Power.pdf.

[4] The Climate Group. SMART 2020, "Enabling the low carbon economy in the information age," 2008, http://www.smart2020 .org/_assets/files/02_Smart2020Report.pdf.

[5] I. Humar, X. Ge, L. Xiang, M. Jo, M. Chen, and J. Zhang, "Rethinking energy efficiency models of cellular networks with embodied energy,' IEEE Network, vol. 25, no. 2, pp. 40-49, 2011.

[6] S. Lambert, W. V. Heddeghem, W. Vereecken, B. Lannoo, D. Colle, and M. Pickavet, "Worldwide electricity consumption of communication networks," Optics Express, vol. 20, no. 26, pp. B513-B524, 2012.

[7] S. S. Sandhu, A. Rawal, P. Kaur, and N. Gupta, "Major components associated with green networking in information communication technology systems," in Proceedings of the International Conference on Computing, Communication and Applications (ICCCA '12), pp. 1-6, February 2012.

[8] C. Han, T. Harrold, S. Armour et al., "Green radio: radio techniques to enable energy-efficient wireless networks," IEEE Communications Magazine, vol. 49, no. 6, pp. 46-54, 2011.

[9] L. Xiang, F. Pantisano, R. Verdone, X. Ge, and M. Chen, "Adaptive traffic load-balancing for green cellular networks," in Proceedings of the IEEE 22nd International Symposium on Personal, Indoor and Mobile Radio Communications (PIMRC '11), pp. 41-45, September 2011. 
[10] T. Chen, H. Kim, and Y. Yang, "Energy efficiency metrics for green wireless communications," in Proceedings of the International Conference on Wireless Communications and Signal Processing (WCSP '10), pp. 1-6, October 2010.

[11] L. Suarez, L. Nuaymi, and J.-M. Bonnin, "An overview and classification of research approaches in green wireless networks," EURASIP Journal on Wireless Communications and Networking (WCN), vol. 2012, article 142, 2012.

[12] C. Belady, A. Rawson, J. Pfleuger, and T. Cader, "Green grid data center power efficiency metric: PUE and DCIE," The Green Grid, 2008.

[13] A. Amanna, Green Communications, Institute for Critical Technology and Applied Science (ICTAS) at Virginia tech, 2009.

[14] M. A. Imran, J. Rubio, G. Auer et al., "Most suitable efficiency metrics and utility functions," EARTH Project Report, Deliverable D2.4, pp. 1-89, 2012.

[15] L. Zhao, J. Cai, and H. Zhang, "Radio-efficient adaptive modulation and coding: green communication perspective," in Proceedings of the IEEE 73rd Vehicular Technology Conference (VTC '11), pp. 1-5, May 2011.

[16] Y. Chen, S. Zhang, S. Xu, and G. Y. Li, "Fundamental trade-offs on green wireless networks," IEEE Communications Magazine, vol. 49 , no. 6 , pp. 30-37, 2011.

[17] H. Hamdoun, P. Loskot, T. O'Farrell, and J. He, "Survey and applications of standardized energy metrics to mobile networks," Annales des Telecommunications/Annals of Telecommunications, vol. 67, no. 3-4, pp. 113-123, 2012.

[18] ATIS Exploratory Group on Green (EGG), "ATIS report on wireless network energy efficiency," Alliance for Telecommunications Industry Solutions, 2010.

[19] Mobile VCE, "Power Amplifiers for 4G and beyond-managing the efficiency, bandwidth and linearity tradeoff," http://www .mobilevce.com/sites/default/files/infostore/GR\%20POWER\% 20AMP.pdf.

[20] G. Auer, O. Blume, V. Giannini et al., "Energy efficiency analysis of the reference systems, areas of improvements and target breakdown," EARTH Project Report, Deliverable D2.3, pp. 1-68, 2012.

[21] H. F. Raab, "Efficiency of doherty RF power-amplifier systems," IEEE Transactions on Broadcasting, vol. 33, no. 3, pp. 77-83, 1987.

[22] H. Claussen, L. T. W. Ho, and F. Pivit, "Effects of joint macrocell and residential picocell deployment on the network energy efficiency," in Proceedings of the IEEE 19th International Symposium on Personal, Indoor and Mobile Radio Communications (PIMRC '08), pp. 1-6, September 2008.

[23] F. M. Ghannouchi, M. M. Ebrahimi, and M. Helaoui, "Inverse class $\mathrm{f}$ power amplifier for WiMAX applications with $74 \%$ efficiency at $2.45 \mathrm{GHz}$," in Proceedings of the IEEE International Conference on Communications Workshops (ICC '09), pp. 1-5, June 2009.

[24] B. Berglund, J. Johansson, and T. Lejon, "High efficiency power amplifiers," Ericsson Review, vol. 83, no. 3, pp. 92-96, 2006.

[25] D. Ferling, A. Ambrosy, S. Petersson et al., "Final report on green radio technologies," EARTH Project Report, Deliverable D4.3, pp. 1-121, 2012.

[26] D. Ferling, A. Ambrosy, S. Petersson et al., "Green radio technologies," EARTH Project Report, Deliverable D4.2, pp. 1-89, 2012.

[27] T. Chen, Y. Yang, H. Zhang, H. Kim, and K. Horneman, "Network energy saving technologies for green wireless access networks," IEEE Wireless Communications, vol. 18, no. 5, pp. 3038, 2011.
[28] 3GPP R1-100387, “Extended cell DTX," 2010, http://www.3gpp .org/ftp/tsg_ran/WG1_RL1/TSGR1_59b/Docs/R1-100387.zip.

[29] M. Imran, A. Ambrosy, O. Blume et al., "Final integrated concept," EARTH Project Report, Deliverable D6.4, pp. 1-95, 2012.

[30] 3GPP R2-101213, "Energy saving techniques for LTE” 2010, http://www.3gpp.org/ftp/tsg_ran/WG2_RL2/TSGR2_69/docs/ R2-101213.zip.

[31] R. Wang, J. S. Thompson, and H. Haas, "A novel time-domain sleep mode design for energy-efficient LTE," in Proceedings of the 4th International Symposium on Communications, Control, and Signal Processing (ISCCSP '10), pp. 1-4, March 2010.

[32] J. Lorincz, A. Capone, and D. Begusic, "Impact of service rates and base station switching granularity on energy consumption of cellular networks," EURASIP Journal on Wireless Communications and Networking, vol. 2012, 342, 2012.

[33] 3GPP R3-100162, "Overview to LTE energy saving solutions to cell switch off/on,” 2010, http://www.3gpp.org/ftp/tsg_ran/WG3_ Iu/TSGR3_66bis/docs/R3-100162.zip.

[34] E. Calvanese-Strinati, M. Kamoun, and M. Sarkiss, "Green network technologies," EARTH Project Report, Deliverable D3.2, pp. 1-101, 2012.

[35] L. Chiaraviglio, D. Ciullo, M. Meo, and M. A. Marsan, "Energyaware UMTS access networks," in Proceedings of the 11th International Conference on Wireless Personal Multimedia Communications (WPMC '08), pp. 1-8, 2008.

[36] L. Chiaraviglio, D. Ciullo, M. Meo, and M. A. Marsan, "Energyefficient management of UMTS access networks," in Proceedings of the 21st International Teletraffic Congress (ITC '09), pp. 1-8, September 2009.

[37] M. A. Marsan, L. Chiaraviglio, D. Ciullo, and M. Meo, "Optimal energy savings in cellular access networks," in Proceedings of the IEEE International Conference on Communications Workshops (ICC '09), pp. 1-5, June 2009.

[38] M. F. Hossain, K. S. Munasinghe, and A. Jamalipour, "A protocooperation-based sleep-wake architecture for next generation green cellular access networks," in Proceedings of the 4th International Conference on Signal Processing and Communication Systems (ICSPCS '2010), pp. 1-8, December 2010.

[39] A. Bousia, A. Antonopoulos, L. Alonso, and C. Verikoukis, "'Green' distance-aware base station sleeping algorithm in LTEadvanced," in Proceedings of the IEEE International Conference on Communications (ICC '12), pp. 1-5, 2012.

[40] M. A. Marsan, L. Chiaraviglio, D. Ciullo, and M. Meo, "Switchoff transients in cellular access networks with sleep modes," in Proceedings of the IEEE International Conference on Communications Workshops (ICC '11), pp. 1-6, June 2011.

[41] F. Han, Z. Safar, S. W. Lin, Y. Chen, and K. J. R. Liu, "Energy-efficient cellular network operation via base station cooperation," in Proceedings of the IEEE International Conference on Communications (ICC '12), pp. 4374-4378, 2012.

[42] Z. Niu, Y. Wu, J. Gong, and Z. Yang, "Cell zooming for costefficient green cellular networks," IEEE Communications Magazine, vol. 48, no. 11, pp. 74-79, 2010.

[43] R. Balasubramaniam, Cell zooming techniques for power efficient base station operation [M.S. thesis], Electrical Engineering, San Diego State University, 2012.

[44] X. Weng, D. Cao, and Z. Niu, "Energy-efficient cellular network planning under insufficient cell zooming," in Proceedings of the IEEE 73rd Vehicular Technology Conference (VTC '11), pp. 1-5, May 2011. 
[45] Z. Niu, "TANGO: traffic-aware network planning and green operation," IEEE Wireless Communications, vol. 18, no. 5, pp. 2529, 2011.

[46] F. Richter, A. J. Fehske, and G. P. Fettweis, "Energy efficiency aspects of base station deployment strategies for cellular networks," in Proceedings of the IEEE 70th Vehicular Technology Conference Fall (VTC '09), pp. 1-5, September 2009.

[47] A. J. Fehske, F. Richter, and G. P. Fettweis, "Energy efficiency improvements through micro sites in cellular mobile radio networks," in Proceedings of the IEEE Globecom Workshops, pp. 1-5, December 2009.

[48] F. Richter and G. Fettweis, "Cellular mobile network densification utilizing micro base stations," in Proceedings of the IEEE International Conference on Communications (ICC '10), pp. 1-5, May 2010.

[49] F. Richter, A. J. Fehske, M. Patrick, and G. P. Fettweis, “Traffic demand and energy efficiency in heterogeneous cellular mobile radio networks," in Proceedings of the 71st IEEE Vehicular Technology Conference (VTC '10), pp. 1-6, 2010.

[50] V. Chandrasekhar, J. G. Andrews, and A. Gatherer, "Femtocell networks: a survey," IEEE Communications Magazine, vol. 46, no. 9, pp. 59-67, 2008.

[51] D. Calin, H. Claussen, and H. Uzunalioglu, "On femto deployment architectures and macrocell offloading benefits in joint macro-femto deployments," IEEE Communications Magazine, vol. 48, no. 1, pp. 26-32, 2010.

[52] Y. Hou and D. I. Laurenson, "Energy efficiency of high QoS heterogeneous wireless communication network," in Proceedings of the IEEE 72nd Vehicular Technology Conference Fall (VTC '10), pp. 1-5, September 2010.

[53] F. Cao and Z. Fan, "The tradeoff between energy efficiency and system performance of femtocell deployment," in Proceedings of the 7th International Symposium on Wireless Communication Systems (ISWCS '10), pp. 315-319, September 2010.

[54] J. Gambini and U. Spagnolini, "Wireless over cable for energyefficient femtocell systems," in Proceedings of the IEEE Globecom Workshops (GC '10), pp. 1464-1468, December 2010.

[55] A. Mukherjee, S. Bhat t acherjee, S. Pal, and D. De, "Femt ocell based green power consumpt ion met hods for mobile net work," Computer Networks, vol. 57, no. 1, pp. 62-178, 2013.

[56] I. Gódor, L. Hévizi, O. Blume et al., "Final report on green network technologies," EARTH Project Report, Deliverable D3.3, pp. 1-131, 2012.

[57] G. Y. Li, Z. Xu, C. Xiong et al., "Energy-efficient wireless communications: tutorial, survey, and open issues," IEEE Wireless Communications, vol. 18, no. 6, pp. 28-35, 2011.

[58] T. C.-Y. Ng and W. Yu, "Joint optimization of relay strategies and resource allocations in cooperative cellular networks," IEEE Journal on Selected Areas in Communications, vol. 25, no. 2, pp. 328-339, 2007.

[59] Y. Yang, H. Hu, J. Xu, and G. Mao, "Relay technologies for WiMAX and LTE-advanced mobile systems," IEEE Communications Magazine, vol. 47, no. 10, pp. 100-105, 2009.

[60] C. Bae and W. E. Stark, "Energy-bandwidth tradeoff with spatial reuse in wireless multi-hop networks," in Proceedings of the IEEE Military Communications Conference (MILCOM '08), pp. 1-7, November 2008.

[61] M. Nokleby and B. Aazhang, "User cooperation for energy-efficient cellular communications," in Proceedings of the IEEE International Conference on Communications (ICC '10), pp. 1-5, May 2010.
[62] Z. Zhou, S. Zhou, J.-H. Cui, and S. Cui, "Energy-efficient cooperative communication based on power control and selective single-relay in wireless sensor networks," IEEE Transactions on Wireless Communications, vol. 7, no. 8, pp. 3066-3079, 2008.

[63] A. Radwan and H. S. Hassanein, "Does multi-hop communication extend the battery life of mobile terminals?" in Proceedings of the IEEE GLOBECOM, pp. 1-5, December 2006.

[64] W. Liu, X. Li, and M. Chen, "Energy efficiency of MIMO transmissions in wireless sensor networks with diversity and multiplexing gains," in Proceedings of the IEEE International Conference on Acoustics, Speech, and Signal Processing (ICASSP '05), pp. IV897-IV900, March 2005.

[65] Y. Gai, L. Zhang, and X. Shan, "Energy efficiency of cooperative MIMO with data aggregation in wireless sensor networks," in Proceedings of the IEEE Wireless Communications and Networking Conference (WCNC '07), pp. 792-797, March 2007.

[66] S. Cui, A. J. Goldsmith, and A. Bahai, "Energy-efficiency of MIMO and cooperative MIMO techniques in sensor networks," IEEE Journal on Selected Areas in Communications, vol. 22, no. 6, pp. 1089-1098, 2004.

[67] H. Kim, C.-B. Chae, G. De Veciana, and R. W. Heath Jr., "A crosslayer approach to energy efficiency for adaptive MIMO systems exploiting spare capacity," IEEE Transactions on Wireless Communications, vol. 8, no. 8, pp. 4264-4275, 2009.

[68] 3GPP R2-094677, "eNB power saving by changing antenna number," 2009, http://www.3gpp.org/ftp/tsg_ran/WG2_RL2/ TSGR2_67/docs/R2-094677.zip.

[69] 3GPP R2-094851, "Number of antennas change," 2009, http:// www.3gpp.org/ftp/tsg_ran/WG2_RL2/TSGR2_67/docs/R2094851.zip.

[70] T. Chen, H. Zhang, Z. Zhao, and X. Chen, "Towards green wireless access networks," in Proceedings of the 5th International ICST Conference on Communications and Networking in China (ChinaCom '10), pp. 1-6, August 2010. 

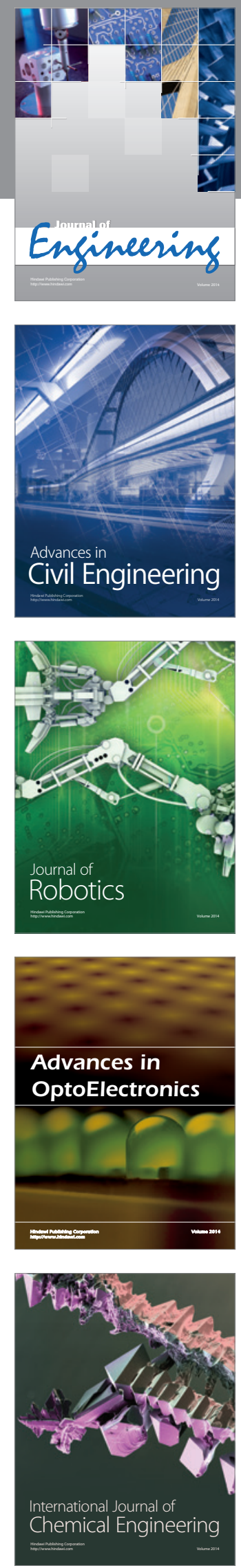

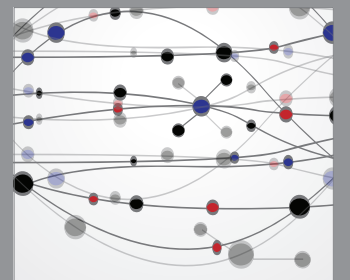

The Scientific World Journal
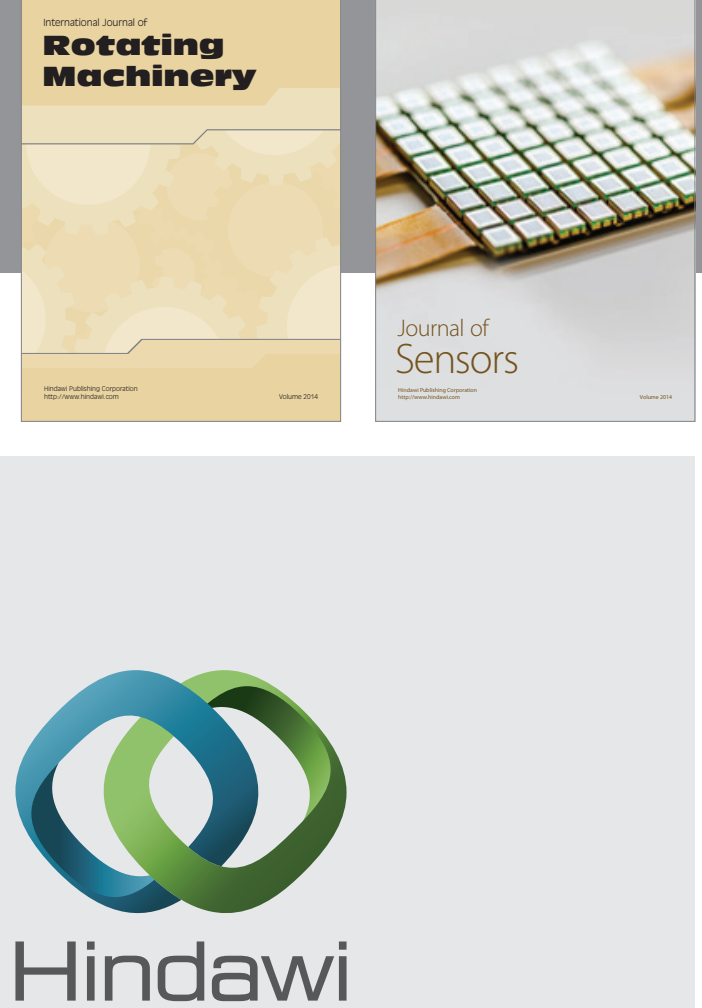

Submit your manuscripts at http://www.hindawi.com
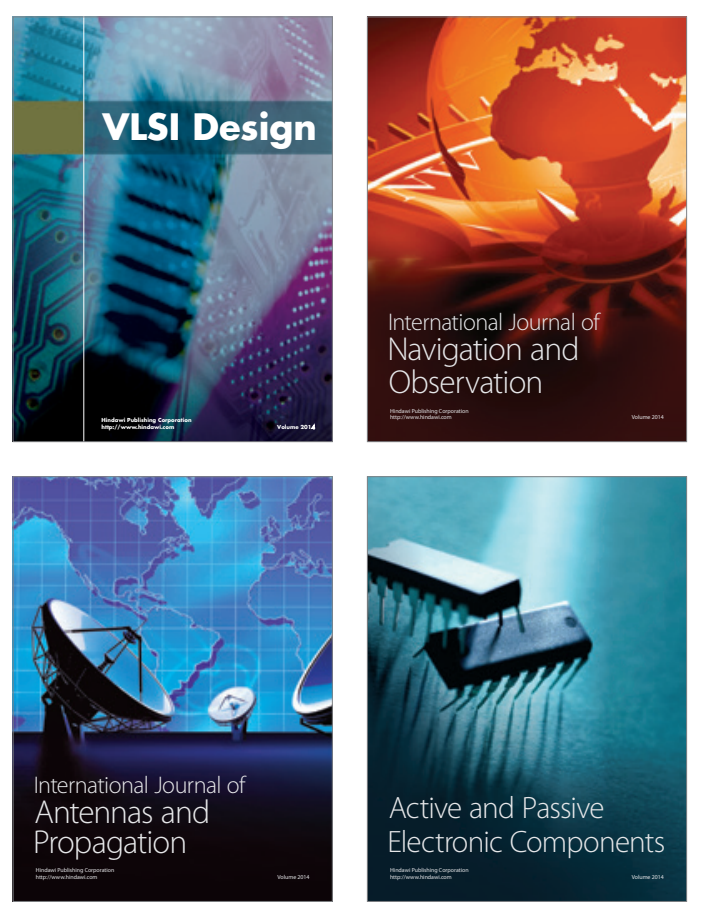
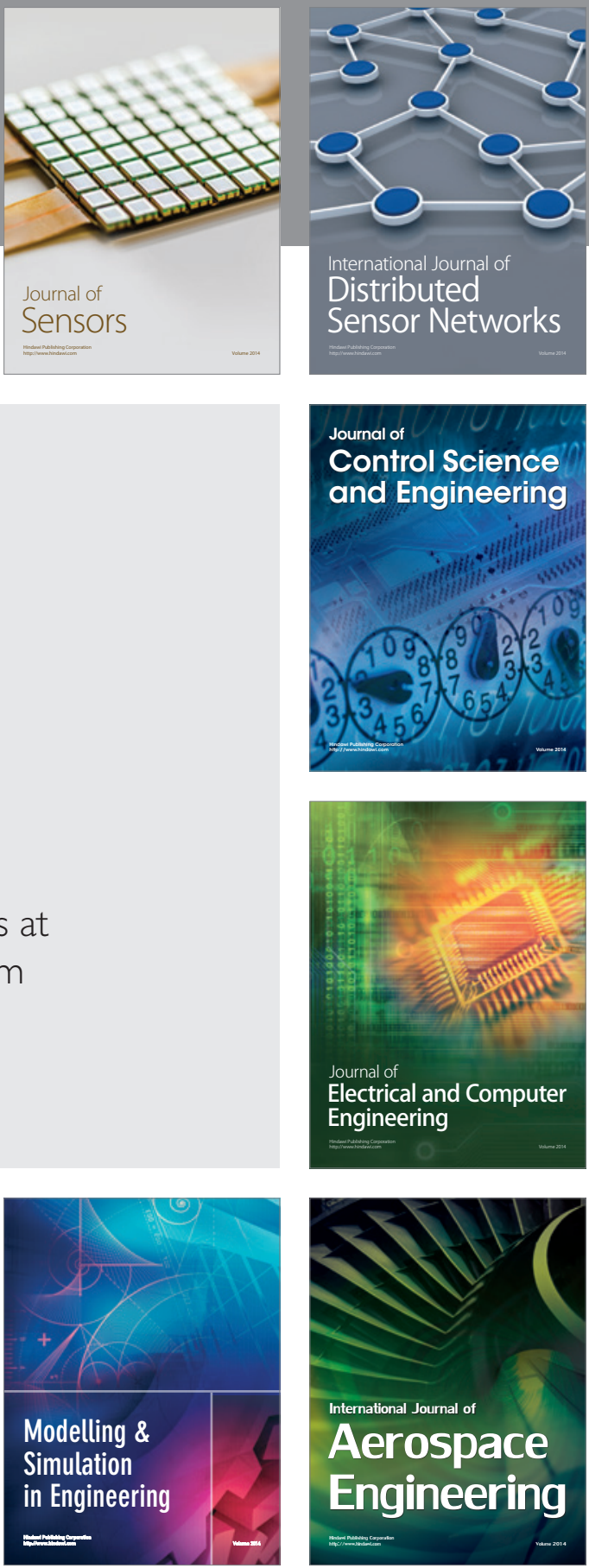

Journal of

Control Science

and Engineering
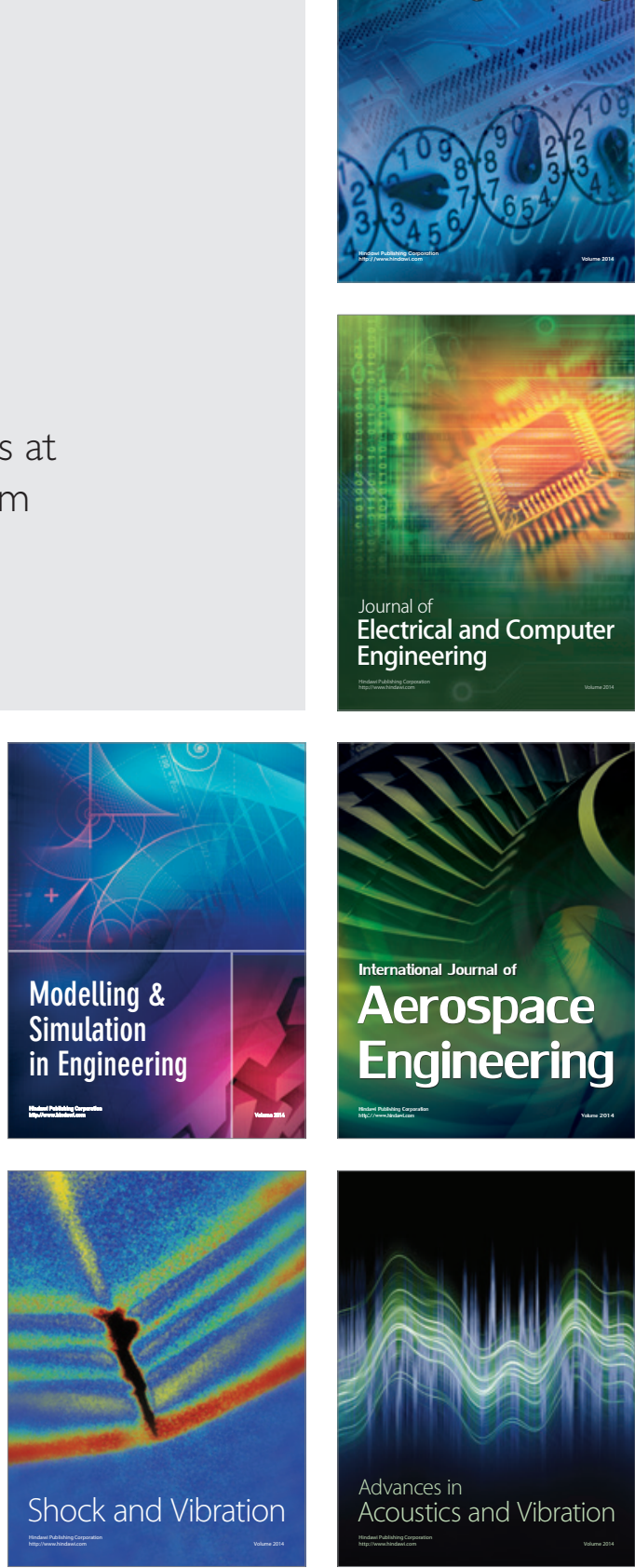